\title{
Public attitudes towards the selection of desirable characteristics in children
}

\author{
Theresa Marteau, Susan Michie, Harriet Drake, Martin Bobrow
}

\begin{abstract}
This paper reports the results of a survey of 973 members of the British public in which attitudes towards methods of achieving desired personal characteristics in their children are compared. While there was little support for the use of gene manipulation to achieve desirable traits in children, the proportion who would consider doing so has more than doubled in the 12 months since the public were last polled on this question. The small but growing public support for the use of gene therapy to enhance human characteristics points to the need for a debate involving the public as well as scientists before such techniques are feasible.
\end{abstract}

(f Med Genet 1995;32:796-798)

Advances in DNA technology make it possible to predict both disease and individual characteristics, such as gender, in unborn children. Human gene therapy has the potential not only to treat disease but also to enhance physical and behavioural characteristics. The extent to which genetic testing and gene therapy should be used to enhance such characteristics is a subject of controversy. The founding editor of Human Gene Therapy has argued that the use of gene therapy should only occur as a medical cure until such time as its safety is established and the ethical dilemmas have been resolved. ${ }^{1}$ One such ethical dilemma concerns the use of gene therapy to enhance characteristics as opposed to treating or preventing disease. One of the arguments used against gene therapy for enhancing human characteristics is its potential to narrow the definition of what it is to be normal. ${ }^{2}$ By contrast with this cautious view, Harris $^{3}$ argues that given that it is acceptable

Received 5 May 1995 Revised version accepted for publication 19 June 1995

Table 1 Attitudes towards enhancing desirable traits in children using genetic manipulation (comparison of views in 1993 and 1994) and vitamin supplementation

\begin{tabular}{llll}
\hline & \multicolumn{2}{l}{ Implanting selected genes* } & Vitamin supplements \\
\cline { 2 - 4 } & \multicolumn{2}{l}{ Proportions saying yes } & \\
\cline { 2 - 4 } If linked with & 1993 & 1994 & 1994 \\
\hline Intelligence & $5 \%$ & $11 \%$ & $41 \%$ \\
Good looks & $2 \%$ & $5 \%$ & $24 \%$ \\
Specific skill & $2 \%$ & $7 \%$ & $29 \%$ \\
Aggression & $5 \%$ & $18 \%$ & $41 \%$ \\
Alcoholism & $5 \%$ & $18 \%$ & $38 \%$ \\
Homosexuality & $4 \%$ & $10 \%$ & $22 \%$ \\
\hline
\end{tabular}

1993 data from Gallup interviews with 529 people aged between 16 and 45 . 1994 data from Gallup interviews with 973 people aged between 18 and 45 .

* Question asked: "Science may some day enable parents to influence the appearance and behaviour of a child by implanting selected genes or altering them. Would you do so?"

† Question asked: "If you could influence the appearance and behaviour of a child by vitamin supplements would you do so?" for people to enhance human characteristics through choices about education and diet, for example, then there is little difference in using genetic technological means to achieve these same ends. It has been further argued that as other medical and surgical interventions are used to enhance such human physical characteristics as height and weight, there is thin justification for excluding gene therapy from such uses. ${ }^{4}$

Public views have played a very small role in these debates. A survey in 1993 showed that while there was strong public support for the use of gene therapy in medicine, there was little public interest in using genetic developments to alter personal characteristics in children. ${ }^{5}$ Over $80 \%$ of those sampled would consider gene therapy if they were dying from an incurable disease. In contrast, no more than $5 \%$ considered gene therapy acceptable for achieving desirable personal characteristics in children.

What was unclear from this survey was the extent to which these attitudes were the result of a reluctance to select characteristics in children for any reason or a reluctance to use gene therapy. The aim of the current study is to compare public attitudes towards achieving desired personal characteristics in children using one of three methods: genetic testing and selective termination of pregnancy; vitamin supplements; and gene manipulation. A second aim was to determine the change in public attitudes towards gene therapy over a one year period.

\section{Methods}

SAMPLE

A representative sample of 973 members of the general public, aged 18 to 45 years, was surveyed by Gallup in July 1994 . The sample was taken from 100 electoral constituencies around Great Britain, and stratified by age, gender, social class, and employment status.

\section{QUESTIONNAIRE}

Attitudes towards the following were measured.

(A) Gene manipulation to achieve one of eight desirable characteristics in their children (table 1). This question was taken from the Daily Telegraph survey. ${ }^{5}$

(B) Prenatal screening and selective termination to achieve a child unaffected by one of eight conditions of varying severity (table 2).

(C) Vitamin supplements to achieve one of eight desirable characteristics in their chil- 
Table 2 Attitudes towards prenatal screening and selective termination*

\begin{tabular}{lcc}
\hline & $\begin{array}{l}\text { \% agreeing } \\
\text { to routine } \\
\text { availability }\end{array}$ & $\begin{array}{l}\text { \% who would or } \\
\text { probably would } \\
\text { use the test }\end{array}$ \\
\hline Child of unwanted sex & 9 & 3 \\
Homosexuality & 10 & 7 \\
Low intelligence & 13 & 3 \\
Missing fingers & 12 & 2 \\
Cancer & 34 & 16 \\
Cystic fibrosis & 47 & 32 \\
Down's syndrome & 65 & 41 \\
Anencephaly & 71 & 63 \\
\hline
\end{tabular}

* Question asked: "Imagine that reliable tests have been developed for each of the following diseases and characteristics. What are your views on testing with the possibility of ending the pregnancy?"

Descriptions were added for the following:

Low intelligence: the child is able to attend regular school but needs extra help.

Missing fingers: two missing fingers on the left hand.

Cancer: in early 30 s that may be difficult to treat

Cystic fibrosis: the child has lung and digestive problem requiring daily treatment. The majority are likely to reach adulthood.

Anencephaly: the child will die soon after birth, usually within an hour.

dren. The wording of this item was similar to that used to assess attitudes towards the use of gene manipulation to achieve the same outcomes.

PROCEDURE

The data were collected during face to face interviews, conducted by a market research organisation, Gallup.

\section{Results}

GENE MANIPULATION

A minority of respondents ( 5 to $18 \%$ ) said that they would consider implanting or changing selected genes to alter aspects of the appearance or behaviour of a child (table 1). This is, nevertheless, more than double the rate of positive responses to this same question one year earlier from 529 respondents of similar age group (16 to 45 year olds). The proportion who would consider using such techniques, were they possible, increased from an average of $4 \%$ across all eight characteristics in 1993 to an average of $11 \%$ in 1994 . There was most interest in using genetic techniques to alter aggressive behaviour and alcoholism.

\section{VITAMIN SUPPLEMENTS}

Between two and four times as many people would consider using vitamin supplements as would consider using gene manipulation to alter the same characteristics (table 1). There was most interest in using vitamins if they could alter intelligence, aggression, and alcoholism. There was least interest in using vitamins to alter sexual orientation.

PRENATAL SCREENING AND SELECTIVE TERMINATION OF PREGNANCY

Very few respondents ( 2 to $7 \%$ ) said that they would use prenatal screening and selective termination to avoid having children with un- desired characteristics or with minor physical or intellectual problems (table 2). However, about double these numbers thought that such a service should be routinely available (9-13\%).

\section{Discussion}

The majority of the public say they would not select or alter their children's behaviour or appearance using gene manipulation, prenatal genetic testing and selective termination, or vitamin supplements. Of these three, the use of vitamins was most acceptable; least acceptable was the use of prenatal genetic testing and termination. While there was relatively little support for the use of gene manipulation to achieve desirable traits in children, the proportion who would consider doing so was significantly more than the proportion reported in a survey a year earlier. ${ }^{5}$

These results suggest that there is a sizeable minority of people who are not averse to altering physical or behavioural characteristics, but are averse to achieving this by altering genes. These differences in attitudes towards gene manipulation and the use of vitamins may reflect several factors: gene therapy is new and therefore a less familiar intervention for most people, and genetic manipulation has negative overtones, partly from past eugenic abuses and partly from futuristic fictional images. Additionally, changing genes may be seen as, in some way, changing a core part of a person, in a way that changing vitamin levels is not considered to do.

The finding that only a minority of the general public consider the use of genetic manipulation to alter non-disease traits as acceptable reflects the results of other surveys. For example, in a survey in 1991, the idea of applying genetic manipulation to curing was comfortable for $71 \%$ of respondents and uncomfortable to only $9.5 \%$. By contrast the idea of applying genetic manipulation to change physical appearances was comfortable to only $4.5 \%$ and uncomfortable to $84 \%{ }^{6}$ Similar results were obtained in the survey conducted by the Daily Telegraph two years later. However, this figure appears to be changing over time. Given the similarity in methodology used in the 1993 and the current survey, that is, the same question was asked by the same survey organisation of the same type of population, it is unlikely that the finding can be ascribed to a methodological difference between the studies. However, it should be noted that the question was asked in the context of different questionnaires, which may have influenced the results.

Coverage of genetic developments on the television and in newspapers, the main sources of information for the public, ${ }^{7}$ has risen rapidlv over the past year. The first gene therapy trials started between the 1993 and 1994 surveys. Many newspaper and television reports greeted these developments with great optimism. This may have resulted in a shift in the reporting of genetic developments from a focus on concerns to more of a focus on their great potential. ${ }^{8}$

Manipulating genes to enhance physical or 
behavioural characteristics, as opposed to its use to prevent or treat disease, is currently considered unacceptable by many scientists and clinicians, and is rejected by the Clothier report on the ethics of gene therapy. ${ }^{9}$ Evidence of the small but growing public support for the use of gene therapy to enhance human characteristics points to the need for a debate involving the public as well as scientists and other interested professional groups. This needs to happen now, before such applications of genetics are technically feasible.

This study was funded as part of a programme grant from The Wellcome Trust entitled "Psychological and Social Implicas of the New Genetics". Theresa Marteau, Susan Michie, and Harriet Drake are supported by The Wellcome Trust.
Anderson WF. Human gene therapy: why draw a line? $f$ Med Philos 1989;14:681-90.

2 Post SG. Selective abortion and gene therapy: reflections on human limits. Hum Gene Ther 1991;2:229-33.

3 Harris J. Wonderwoman and Superman: the ethics of human biotechnology. Oxford: Oxford University Press, 1992

4 Miller HI. Gene therapy for erd University Press, 1992. 316-7.

5 The Daily Telegraph. A mighty no to designer babies. 16 August 1993

6 Martin S, Tait J. Attitudes of selected public groups in the UK to biotechnology. In: Durant J, ed. Biotechnology in public. London: Science Museum for the European Federation of Biotechnology, 1992.

7 Eurobarometer 39.1. Biotechnology and genetic engineering. what Europeans think about it in 1993. Brussels: INRA for the Commission of European Communities, 1993.

8 Durant J, Hansen A, Bauer M. Public understanding of the new human genetics. In: Marteau T, Richards M, eds. The troubled helix: social and psychological implications of the new human genetics. Cambridge: Cambridge University Press, (in press).

9 Report of the Committee on the Ethics of Gene Therapy London: HMSO, 1992. 